\title{
Getting on Smokin' Route 66: tobacco promotion via Russian mass media
}

Tobacco advertising appears to be a most significant factor contributing to a major increase in tobacco use in Russia, especially among younger generations. This impact might be somewhat stronger than in Western countries because Russia has been isolated and virtually unexposed to Western-type advertising for decades. Thus, the population's sensitivity to the novelty and glamour of Western tobacco advertisements is extremely high. The effects of advertising are suggested by the dramatically increasing prevalence of smoking among the Russian population, especially the young, in recent years-for example, according to the State Research Centre for Preventive Medicine, smoking prevalence among school children aged 13-16 years increased from $31.5 \%$ in 1992 to $42.5 \%$ in $1993 .{ }^{1}$ The early 1990 s saw perhaps the heaviest influx of tobacco advertising into Russia. ${ }^{2}$ Throughout the Soviet era, Western-manufactured cigarettes were more socially acceptable and more highly desirable than Soviet-made tobacco products because they symbolised an enticing Western lifestyle. Now these products are widely available, and continue to gain popularity. Advertisements for West cigarettes, with its "Test the West" slogan, have been one of the most common advertisements seen on billboards and posters.

The tobacco industry aggressively promotes the perceived "wealthy lifestyle with Western cigarettes" among youth by advertising and sponsoring popular events in ways that are familiar to all in the West. In 1994, for example, the European tobacco industry offered a lottery prize of a Suzuki Samurai decorated with the $\mathrm{H} \& \mathrm{~B}$ brand logo (figure 1). Efforts of the Ministry of Health of the Russian Federation, the National Committee on Anti-Monopoly Politics, and a few other active anti-tobacco groups to reduce the impact of tobacco advertising have brought results. Since 1 January 1996, tobacco (and alcohol) advertising via television has been prohibited by federal law. However, according to the National Committee on Anti-Monopoly Politics, this law was violated at least 12 times in the period from January to June 1996. Furthermore, tobacco advertisements continue to appear in the Russian press.

In their attempts to prosper from the Russian cigarette market, the transnational tobacco corporations (TTCs) appear to have recently intensified their successful Western advertising strategy. They are now promoting their cigarette brands as an indispensable part of the Western lifestyle, thus trading on the

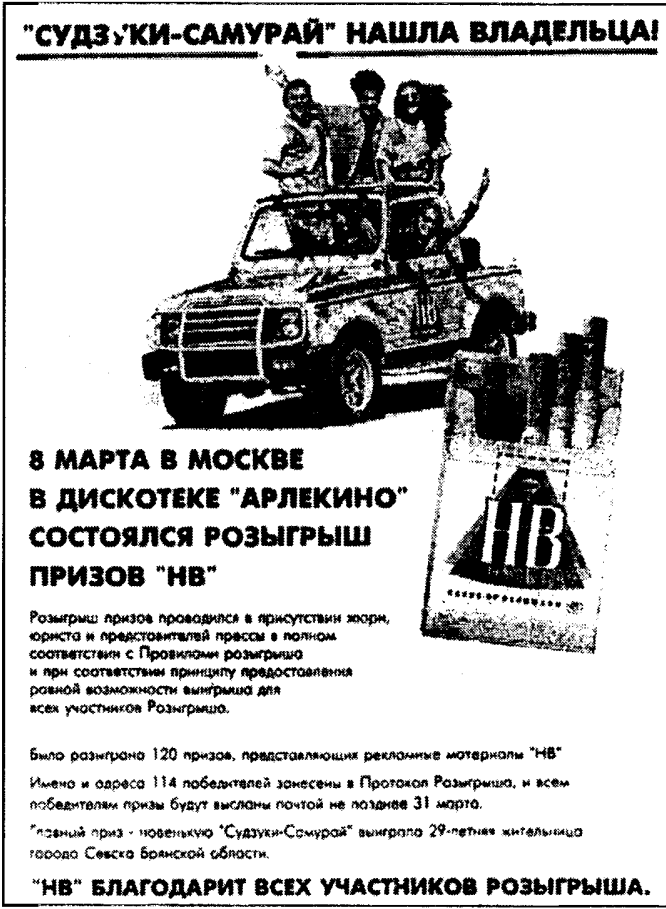

Figure 1 The prize for a lottery sponsored by $H \mathcal{E} B$ cigarettes was a Suzuki Samurai decorated with the brand's logo.

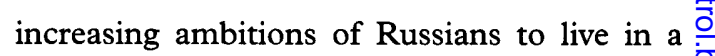
free, Western-type society. Recent issues of $\frac{5}{3}$ some popular Russian magazines and newspapers published advertisements of distinctly Western orientation (figure 2). The full-page L\&M advertisement "A date with America" 을 was published in Sobesednik (No 13, 1996), a 을. very popular newspaper among the young. It features just about every lifestyle attribute $\widehat{N}$ desired by Russian youth: happy young people $N$ wearing leather jackets and jeans, travelling on

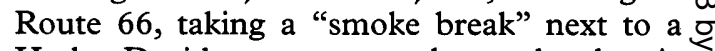
Harley-Davidson motorcycle and electric o guitar, with a Sands Motel and a bus heading $\overparen{D}$ for Los Angeles in the background. And, of $\stackrel{\oplus}{+}$ course, a pack of L\&M cigarettes! How could 0 we possibly imagine a "date with America" without them?

Some popular newspapers and magazines $\stackrel{\mathbb{Q}}{\varrho}$ are exhibiting explicitly sarcastic attitudes towards tobacco-and-health issues and the $\delta$ anti-tobacco movement in general. For example, material recently published in the 흥 "Health" section of Nedelya Weekly (No 10, 1996) presented a short review of a 384-page book, The encyclopedia of safe smoking: how smokers can preserve their health. The book was compiled, the review tells us, from three unspecified American publications. Presum- 


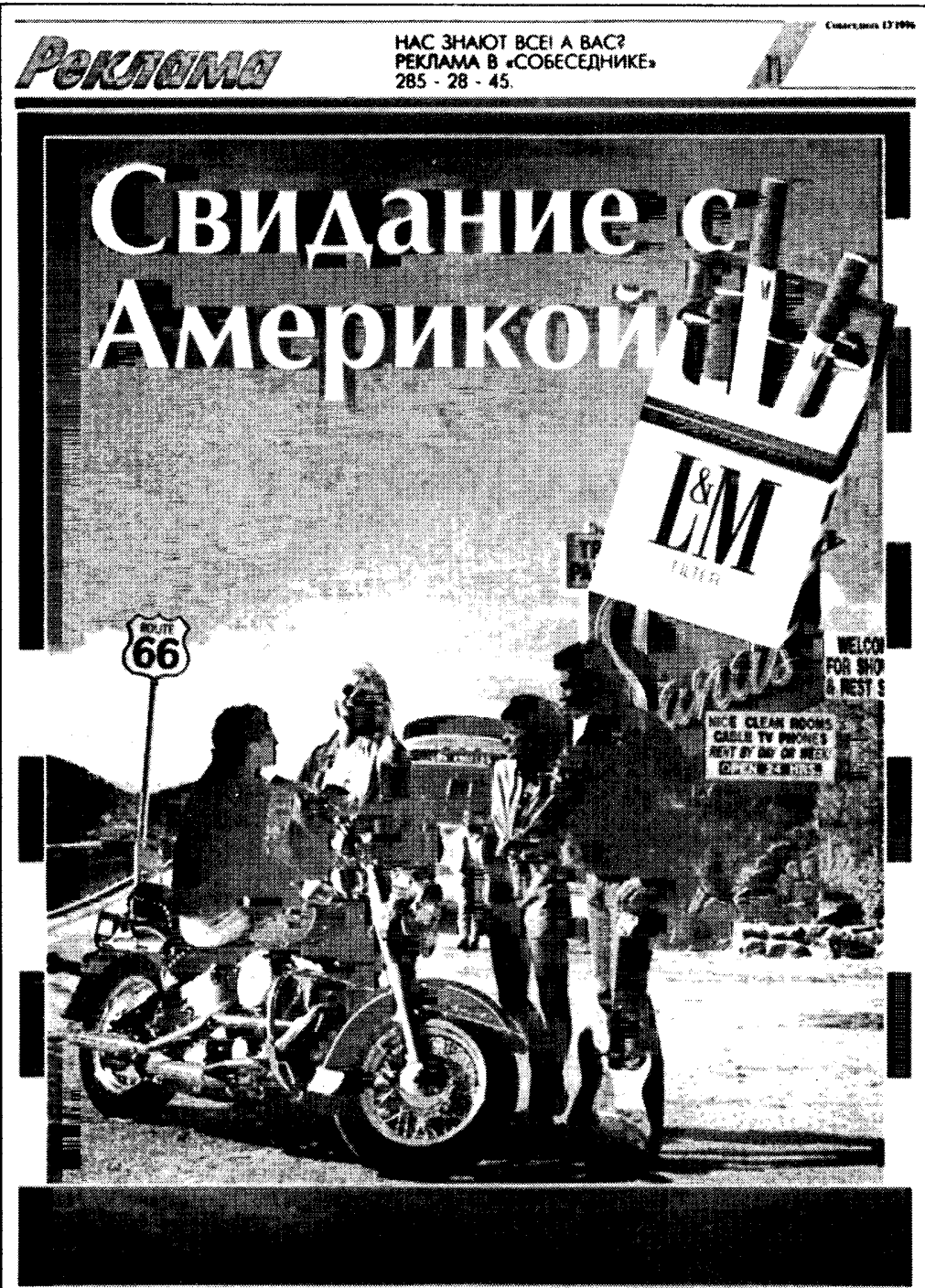

МИНЗДРАВ ПРЕДУПРЕЖААЕТ: КУРЕНИЕ ОПАСНО АЛЯ ВАШЕГО ЗДОРОВЬЯ.

Figure 2 An LEM advertisement, " $A$ date with America”, featured many symbols of Western lifestyles.

ably, the American sources were mentioned to increase the readers' interest towards the new "opus". According to the reviewer, the book provides helpful advice for smokers living in an industrial society on how to "enjoy life" (read "enjoy cigarettes") and how "not to vanish by the age of 40 ". To be fair, I must note that the reviewer mentions the last chapter of the book devoted to a "systemic" smoking cessation method. It appears, however, that quitting is presented in The encyclopedia of safe smoking as a low-priority option inferior to the "pleasurable" smoking lifestyles combined with "life-saving" relaxation techniques. Interestingly, at the end the reviewer offers his own tips on safe smoking, including avoiding smoking before breakfast, in the sauna, when walking in a hurry, and when there is no strong desire to smoke. Throughout, the reviewer emphasises pleasure as the main purpose of smoking.

In a recent article (No 23, 23 July 1996), Kommersant, an analytical weekly, attempts to analyse the current tobacco and alcohol advertising situation in the country. This article quite sarcastically criticises the activities of the National Committee on Anti-Monopoly Policy aimed at banning tobacco and alcohol advertising. It is full of similar industry pearls: "It has been proven a long time ago that alcohol drinking may be influenced by everything but advertising, which steers only consumers' preferences"; further: "Indeed, there was no advertising during the Soviet Power, yet the people were drinking more and more over time." But the pinnacle of the author's speculations about the role of advertising may be this one: "Advertising videos do not promote alcohol abuse; on the contrary, they increase the culture of consumption of alcohol-containing fluids. The characters portrayed in these videos are always well-dressed and situated in an affluent environment, not in some kind of dumpster." This interesting observation can be expanded to cigarette smokers in tobacco advertisements, who are not depicted in shelters for the homeless, either.

Given the above examples, it seems that the Russian press still has a long way to go in achieving an understanding of the magnitude of the smoking-and-health problem and realising its role in promoting the current and future health of the nation.

ALEXANDER V PROKHOROV Department of Behavioral Science, MD Anderson Cancer Center, University of Texas,

1515 Holcombe Boulevard, Houston, Texas 77030,USA email:aprokhor@notes.mdacc.tmc.edu

1 Tkachenko GB. Tobacco smoking and public health in Russia. In: Demine AK, ed. Smoking or health in Russia? Report No 3, Report Series on Policy in Health Protection. Moscow: Health and Environment Foundation, 1996:28-155.

2 Kholmogorova GT, Prokhorov AV. West goes East: the new tobacco situation in Russia. Tobacco Control 1994;3:145-7. 